\title{
Structural Insights on Transformation Products of the Anticoagulant Drug Warfarin
}

\author{
WIPERT JANNIK VON TÖRNE ${ }^{1}$ AND CHRISTIAN \\ PIECHOTTA $^{2}$
}

${ }^{1}$ Federal Institute for Materials Research and Testing (BAM)

${ }^{2}$ Bundesanstalt für Materialforschung und -prüfung

Presenting Author: Wipert-Jannik.von-Toerne@bam.de

Warfarin (Coumadin) is one of the most popular anticoagulant drugs used as a therapeutic in humans to prevent thrombosis, atrial fibrosis, and fibrillation since the 1950s. Because of its ability to hinder blood coagulation by blocking vitamin $\mathrm{K}$ depending carboxylation of blood clotting precursors, it is also used as a rodenticide worldwide, causing fatal internal bleedings in targeted species. In more recent times, it has been partially substituted by far more potent anticoagulant rodenticides (ARs), so-called superwarfarins. ${ }^{[1]}$

Numerous studies confirm bioaccumulation of ARs in nontarget-animals and wildlife by secondary and tertiary poisoning. Up to now, relatively little is known about persistence of ARs in aquatic or terrestrial environments and within the food chain. There is far less known about naturally or technically (e.g. during waste water treatment) formed transformation products (TPs) remaining in different compartments of the environment. ${ }^{[2-5]}$

Herein, we present liquid and gas chromatographic methods coupled with (high-resolution) mass spectrometry for the analysis of warfarin's TPs. Methodologies such as UVirradiation, ozonation, and chlorination were utilized to simulate primarily technical water treatment, as well as, abiotic transformation processes. Examination of resulting compounds by numerous analytical methods has provided first insights into a multitude of formed substances. Moreover, the oxidative phase I metabolism was mimicked by an electrochemical flow cell with the aim to synthesize and confirm major metabolic products via a nonbiologically mediated process. ${ }^{[6-8]}$ The further aim is the toxicological assessment of relevant TPs, as well as, the quantification of warfarin and its TPs under environmentally relevant conditions employing the introduced methodologies.

References:

[1] Wardrop, \& Keeling (2008), Br J Haematol 141, 757-763.

[2] Regnery, Friesen, Geduhn, et al. (2018), Chemistry Letters.

[3] Regnery, Parrhysius, Schulz, et al. (2019), Water Res 167, 115090.

[4] Regnery, Schulz, Parrhysius et al. (2020), Sci Total Environ 740, 139905.

[5] Nakayama, Morita, Ikenaka, et al. (2019) J Vet Med Sci 81, 298-313.

[6] Faber, Vogel \& Karst (2014) Analytica Chimica Acta 834, 9-21.

[7] von Gunten, (2003) Water Res., 1443-1467.

[8] Peuravuori \& Pihlaja (2009) Anal Bioanal Chem 394, 1621-1636. 